\title{
вм] Global Health Boundary-spanning: reflections on the practices and principles of Global Health
}

\author{
Kabir Sheikh, ${ }^{1}$ Helen Schneider, ${ }^{2,3}$ Irene Akua Agyepong, ${ }^{4}$ Uta Lehmann, ${ }^{2}$ \\ Lucy Gilson ${ }^{5,6}$
}

To cite: Sheikh K,

Schneider H, Agyepong IA, et al. Boundary-spanning: reflections on the practices and principles of Global Health. BMJ Global Health 2016;1:e000058.

doi:10.1136/bmjgh-2016000058

Received 6 April 2016 Revised 30 April 2016 Accepted 5 May 2016

\section{CrossMark}

\footnotetext{
${ }^{1}$ Public Health Foundation of India, New Delhi, India ${ }^{2}$ University of the Western Cape, Cape Town, South Africa

${ }^{3}$ SAMRC/UWC Health

Services to Systems

Research Unit, Cape Town, South Africa

${ }^{4}$ Greater Accra Regional Health Directorate, Ghana Health Service, Accra, Greater Accra Region, Ghana ${ }^{5}$ University of Cape Town, Cape Town, South Africa ${ }^{6}$ London School of Hygiene and Tropical Medicine, London, UK
}

\section{Correspondence to}

Dr Kabir Sheikh;

kabir.sheikh@gmail.com

\section{ABSTRACT}

As Global Health evolves, not merely as a metaphor for international collaboration, but as a distinct field of practice, it warrants greater consideration of how it is practiced, by whom, and for what goals. We believe that, to become more relevant for the health systems and communities that are their intended beneficiaries, Global Health practices must actively span and disrupt boundaries of geography, geopolitics and constituency, some of which are rooted in imbalances of power and resources. In this process, fostering cross-country learning networks and communities of practice, and building local and national institutions with a global outlook in low and middle-income countries, are critically important. Crucially, boundary-spanning practices in Global Health require a mindset of inclusiveness, awareness of and respect for different coexisting realities.

\section{GLOBAL HEALTH: A FIELD OF PRACTICE?}

In the past decade, the international development and public health communities have witnessed the emergence of the terminology of Global Health and its widespread use in different contexts. This period has coincided with transformative changes, including the culmination of a shift away from the centrality of multilateral agencies such as the WHO, towards diffuse forms of Global Health governance, involving a range of influential and entrepreneurial actors across the global stage. ${ }^{1}$ It has also seen greatly increased flows of funding to the disease burdens of the south, from a combination of bilateral, publicprivate partnership and philanthropic sources. ${ }^{2}$ Global Health programmes, departments and technical agencies have sprung up across the Global North in response to the many new international opportunities offered by this increased funding, animating much of the contemporary debate on the meanings of Global Health.

\section{Key questions}

What is already known about this topic?

- Global Health is a powerful metaphor for collective action to achieve universal health goals, and has animated many individual and institutional practitioners.

- While the past decade has seen Global Health emerge as a putative field of practice, little is known or discussed about how it can and should be practised.

- Actors in the Global North dominate the field of Global Health, often as a result of financing flows from Northern countries.

What are the new findings?

- Global Health evokes an ideal of universality, yet it actually consists of multiple demarcations and 'territories' of practice, each with its own frame for planning, action and debate.

- Bridging boundaries between different health system contexts; between research, policy and field practice; and between local, national and global experiences and priorities, is often not seen as the purview of Global Health practice.

- The practice of Global Health should entail effort to traverse these boundaries, to become more relevant for the health systems and communities that are its intended beneficiaries.

\section{Recommendations for policy}

- Boundary-spanning approaches can be useful in guiding the implementation and institutionbuilding processes necessary to achieve Global Health goals.

- Learning networks, communities of practice and learning organisations with a global outlook in low and middle-income countries can be effective boundary-spanners, and need to be supported.

- Boundary-spanning practices in Global Health need to challenge current dispensations of power, and operate with a mindset of inclusiveness, awareness of and respect for different coexisting realities. 
In this transforming milieu, for some, Global Health is a reformulation of International Health (or Tropical Medicine before that). For others, it is the arena of response to threats to health posed in a globalised world: whether HIV/AIDS, Zika, climate change or the effects of transnational corporations. For yet others, it signifies the global architecture of collaboration and cooperation across countries and health systems, in what is seen to be a generally beneficial impact on the world. ${ }^{3}$ This period has also seen Global Health emerge as a putative field of practice, with a number of individuals and institutions identifying themselves as Global Health practitioners (as do the authors of this article). Common connotations of Global Health as a practice are, for instance, the efforts of multilateral organisations and partnerships in financing disease control programmes or health sector reforms in low and middle-income countries (LMIC), the actions of governments in cooperating and coordinating to improve crossborder health security, international advocacy by networks for conditions such as HIV/AIDS, tobacco control or noncommunicable diseases and scientific research in LMIC conducted through international collaborations, typically between Northern universities or institutes, and organisations based in the relevant country.

Stuckler and $\mathrm{McKee}^{4}$ have elaborated how Global Health is a malleable metaphor to which practical significance can be attached by referring to a specific sphere of activity, whether it be financing and programming, organisational governance, health security, public health advocacy and norm-setting or knowledge production and discourse. Yet even this advanced taxonomy tells us little about the value proposition of Global Health as a field of practice, or of how it can and should be practised. In the absence of discussion on the notional value of Global Health practice, the term frequently gets framed and invoked in a manner that tends to validate the interests and practices of those actors with the voice and the power to control the relevant discourse. ${ }^{5}$ In this process, a range of other, equally valuable practices, including those rooted in countries and institutions in the Global South, potentially get neglected and excluded from the understanding of Global Health.

In this opinion piece, we aim to open a window of debate about alternative and additional perspectives on the idea and the practices of Global Health. We believe that Global Health has huge potential as a framework for action and change, but greater consideration of how it is practised, by whom and for what goals can increase its value as a field of practice. Our perspectives on Global Health emanate from our personal and collective experiences as health policy and system researchers and practitioners based in low and middle-income health systems, including, but not limited to our engagements with, respectively, an international membership organisation (http://www.healthsystemsglobal.org) and a series of global conferences (http://healthsystemsresearch.org/ hsr2016/), African Health Policy and Systems Research
(HPSR) field-building initiatives (http://www.hpsa-africa. org, http://www.chesai.org,), and national-level research training and policy collaboratives in India (http://www. phfi.org/keystone), and an emerging West African collaboration of institutions and individuals to support and promote health policy and systems research and practice in the subregion.

\section{BOUNDARIES IN GLOBAL HEALTH AND THE IMPORTANCE OF 'BOUNDARY-SPANNING'}

In shaping our understanding of the practices of Global Health, we consider that, at its heart, 'global' evokes an ideal of holism and universality-the existence of a shared set of concerns and experiences, and our shared commitment to and investment in the improvement of health and healthcare worldwide. In reality, however, the world of Global Health actually contains multiple demarcations and 'territories' of practice, each with its own frame for planning, action and debate, and often separated by operational, linguistic and philosophical boundaries. Some of the critical demarcations in Global Health are those that lie between:

- Health defined broadly including its social determinants, and a focus on healthcare. ${ }^{6}$

- Different disease control or service delivery priorities within the health sector, and between these priorities and cross-cutting support functions within the sector (such as human resource planning, development and management). ${ }^{7}$

- Different health systems and contexts, often seen to be incomparable. ${ }^{8}$

- Research, policy and field practice in health. ${ }^{9}$

- Local, national and global experiences and priorities. ${ }^{10}$

Boundaries like these serve many important purposes, including the creation of institutions and structures with a specific focus, and simplifying decisions for decisionmakers within them. However, our frequent inability to bridge these boundaries in the pursuit of shared goals creates obstacles to achieving beneficial change for our communities, and especially those most marginalised in our societies and by global forces. This inability can constrain opportunities for the coordinated action and innovation required to undertake complex tasks and address complex problems, such as those that we encounter in health and development.

In a sphere of action that is riven by boundaries of different types, practising Global Health should necessarily entail effort to traverse different types of boundaries (and not merely the geo-political ones). Of the interfaces listed above, the first two, namely boundaries between healthcare and action on the social determinants of health, and between different programmes and functions within the health sector, are gradually receiving well-deserved attention in the Global Health sphere. ${ }^{11}$ They are also foregrounded in the articulation of the sustainable development goals, in which health goals are unified and placed firmly within a broad social 
development agenda, and in the global push for Universal Health Coverage.

However, disrupting the other boundaries is seldom seen as being within the purview of Global Health, and we focus our discussions on these. Yet they are important because all Global Health thinking needs to be rooted in the real world of local knowledge and experiences, whether on the management of infectious diseases, results based financing or communities and their experiences. Conversely, global guidance on these and other topics needs to find a fit with country and local contexts that are not necessarily the same as where they are drawn from.

The notion of 'boundary-spanning', described as the practices of 'reaching across borders, margins, or sections to build relationships, interconnections and interdependencies in order to manage complex problems', ${ }^{12}$ is, therefore, of relevance to the development of Global Health thinking. Boundary spanning in Global Health requires a mindset for learning-that goes upstream: to draw out general or global lessons from the particulars of the local; downstream: for effectively applying global guidance for local practice and evaluating its relevance; and also laterally: for learning from different and comparable contexts.

\section{BOUNDARY-SPANNING STRATEGIES AND BOUNDARY ORGANISATIONS}

There is now international consensus, particularly since the Ebola epidemic, that strong, resilient and equitable health systems are required at country level. There are ultimately no shortcuts and no alternatives to strengthening country and local health systems, if we are to achieve global goals of health for all. ${ }^{13}$ We elaborate on some strategies and contexts that can facilitate effective boundary-spanning practices in Global Health to achieve these goals, and the type of organisations that can undertake these practices.

\section{Working across contexts: conversations and comparisons}

Fostering cross-country learning networks across LMICs, which themselves cut across boundaries such as those of community/national level organisation, researcher/policymaker, educator/researcher, and create global communities of practice, are of key importance in this respect.

Networks spanning Southern country learning organisations, such as EQUINET (the Network on Equity in health in Southern and Eastern Africa, http://www. equinetafrica.org), and the People's Health Movement (http://www.phmovement.org), for example, are playing important roles in inculcating a universal outlook and global leadership for health equity. It is important that conversations across countries go beyond a simple comparison of health systems. Opportunities for exchange of perspectives between country level health planners, practitioners and researchers can generate rich insights and mutual learning, especially if the systems share similar challenges. ${ }^{14}$

Three interconnected initiatives that are strengthening African HPSR networks also provide useful examples of boundary-spanning conversations. CHEPSAA, the Consortium for Health Policy and Systems Analysis in Africa, was a consortium of 11 African and European university-based groups involved in teaching and research (2011-2015). Working towards the goal of fieldbuilding for HPSR in Africa, CHEPSAA's working processes enabled the deliberate sharing of experience across geographic and academic/policy boundaries, which generated practical benefits for both the southern and northern partners. These included a new generation of HPSR organisational and field leaders, stronger educational programmes and enhanced linkages with policymakers and health system practitioners. CHEPSAA's teaching materials are open-access and available online, which is extending their reach and influence. A common goal, collaborative leadership practices, the incremental development of activities and equally-shared funding for all partners (from the European Union), provided CHEPSAA's enabling environment.

Linked to CHEPSAA, the Collaborative for Health Systems Analysis and Innovation (CHESAI), funded by the IDRC, Canada, has sought to consolidate a Southern-based HPSR community of practice with a Cape Town hub. CHESAI's activities bring academics, researchers, policymakers and managers together to test new forms of engagement as well as debate current research from different perspectives, develop shared understandings and coproduce knowledge through joint writing. The filigree of relationships established through multiple interconnected activities has allowed mutual exchange and learning, and is spreading through other networking initiatives.

The West and Central African Health Policy, Systems and Maternal, Newborn, Child and Adolescent Health (MNCAH) partnership is a third South-South capacity building and networking partnership for leadership, research and practice to support health policy and systems strengthening for improved MNCAH. Starting full scale in 2016, it has been preceded by 2 years of consultations between individuals and institutions in the subregion, and is funded by the IDRC. Its partners include some linked to CHEPSAA, and its West African Network of Emerging Leaders draws in both CHEPSAA's Emerging Leaders and the Emerging Voices for Global Health network (http://www.ev4gh.net).

\section{Disrupting research/policy/field practice demarcations}

It is now well established that policymaking is not merely a technical exercise guided by defined knowledge products but instead is commonly the result of a complex and messy interplay of ideas and interests. Global Health can become more relevant by recogniing this reality, promoting transparent and ethical practices that actively bridge and blur conventional boundaries of research, 
policy and field practice and discarding out-of-date frameworks that tend to separate them neatly. ${ }^{15}$

Engaging policymakers, practitioners, researchers and civil society actors equally is a key concern of Health Systems Global (HSG), the international membership organisation dedicated to promoting health systems research and knowledge translation. This has been tackled in different ways, with HSG focusing equally on recruiting members who self-identify as planners, practitioners, activists and researchers, and the organisational membership is healthily distributed across those categories. Thematic groups such as social science approaches for research and engagement in Health Policy and Systems $(\mathrm{SHaPeS})$ have explicitly oriented their activities to focus not on merely producing and showcasing evidence, but on varied forms of engagement with a range of health policy actors.

Moreover, the global HSR Symposia allow submissions for a number of 'field-building' dimensions, including innovative health system practice, knowledge translation and capacity building, which are tailored explicitly for policymakers and practitioners. A new programme is being led by the Alliance for Health Policy and Systems Research to bring more policymakers into engagement with the HSR community at the 2016 Symposium. Civil society representation in the Symposia has developed over time, nurtured by groups involved in Participatory Action Research, and those linked to the People's Health Movement.

The African networks discussed above were also all designed to enable relationship-building between those based in the research, policy and practice worlds. CHEPSAA worked specifically with the understanding that researchers and practitioners need a wide array of competencies to work in the field, and many are practicebased. Its HPSR teaching materials, for example, were developed collaboratively, while the teaching process itself brought academics and managers together to learn from each other as well as providing opportunities for newer teachers to develop their craft. CHESAI has meanwhile supported an 'embedded' approach to HPSR, advocated in the WHO's HPSR Strategy. ${ }^{16}$ In this approach, fuelled by an emerging body of participatory and iterative methodologies, HPSR is increasingly being coproduced by researchers, policymakers and field practitioners, contributing to its greater utility in guiding real-life decisions. ${ }^{17} 18$ The more recent West African initiative will also take forward these approaches.

\section{Reconciling local, national and global contexts: learning organisations in the Global South}

Boundary spanning in Global Health requires new capacities for the combination of scholarly and political work needed to influence ideas and interests, policies and practice. These include the capacities to bridge and reconcile local, national and global contexts, to broker key dialogues with health system practitioners/planners and between them and community level organisations, and to explore new ways of producing and communicating research knowledge for maximum impact, without forsaking rigour.

KEYSTONE is a national-level collaborative of 13 Indian organisations, including research organisations, universities, civil society networks and government departments, convened by the Public Health Foundation of India (PHFI), in its capacity as the nodal institute of the Alliance for Health Policy and Systems Research. KEYSTONE has three objectives: to deliver high-quality training in health policy and systems research, to develop institutional capacity to deliver a global standard of research training, and to channel these towards responding to health system needs.

The convening team drew extensively on the 13 collaborating partners in designing the programme, and major inputs also came from an international advisory board drawn from the London School of Hygiene and Tropical Medicine, the Nossal Institute of Global Health, the Johns Hopkins Bloomberg School of Public Health, the University of Cape Town (UCT), the University of the Western Cape (UWC) and from the CHEPSAA initiative. KEYSTONE's similarities with CHEPSAA include a shared focus on ensuring relevance for local communities and the health system, facilitated by their being convened, respectively, in a foundation (PHFI) and universities (UCT, UWC) of national standing.

KEYSTONE also spun off a major initiative in India to develop a national-level platform for research of direct relevance to country health systems and programmesthe National Knowledge Platform. The Platform is expected to institutionalise key boundary-spanning functions that were part of the KEYSTONE vision, including sourcing local knowledge to inform national priorities for programming and research, and the coproduction of research by practitioners and policymakers to encourage better utilisation of knowledge in decision-making.

Learning organisations based in countries of the Global South are critically positioned to support capacity development to bridge local, national and global contexts. They include the universities mandated to train the foundations and think tanks bringing new energy to the endeavour of bridging the research and policy worlds, NGOs and groups who work with community organisations, as well as other varieties of independent or parastatal 'boundary organisations' mandated to improve local and national health systems. ${ }^{19}$ The Thai International Health Policy Programme is widely known, for example, as a think tank bridging research and policy and also committed to the task of capacity development. Such organisations need to be supported to perform boundary-spanning functions and must be supported to develop robust governance mechanisms that promote their catalytic and energising roles.

\section{PRINCIPLES TO GUIDE PRACTICE}

Boundary-spanning as a principle of practice involves engaging with stakeholders and ideas across silos, and emphasises positive or productive power in the hands of 
actors, to 'organise action through consensual communication' ${ }^{20}$ The Global Health initiatives described in this paper benefited from enabling contexts, including:

- Dedicated funding support to (relatively) capacitated institutions in the Global South invested in building capacity in other local institutions, hence enabling sharing of resources.

- Strong pre-existing relationships between Northern and Southern, and Southern and Southern partners, bound by frameworks enabling mutual learning and benefit, shared commitment to common goals, and often led by Southern partners.

- Pre-existing regional and global networks that linked together heterogeneous organisations in different settings, and that facilitated the development of relationships over time.

Some types of boundaries of geography, geopolitics and constituency are rooted in and perpetuate entrenched power imbalances. While popular rhetoric in the Global Health field frequently involves exhortations to exert more political power to ensure action and meet targets, effective boundary-spanning can also be contingent on questioning one's own power and privileges. As a Global Health practitioner, it can be important to know when to withdraw and allow local actors and institutions to take over.

Effective boundary-spanning requires a mindset of inclusiveness, awareness of and respect for different coexisting realities, which is often missing in current Global Health thinking and action. We believe that current global movements-including the sustainable development goals, with their encompassing focus on healthier societies and the push for universal health coverage, with its lofty ideals of inclusiveness and collective social responsibilityare progressive steps towards strengthening country and local health systems, and represent guiding lights for the international development community. Boundaryspanning, as an approach to Global Health practice, can orient the processes of implementation and institutionbuilding that can make these goals a reality.

\section{Handling editor Seye Abimbola}

\section{Twitter Follow Kabir Sheikh at @docsheikh}

Contributors KS and HS prepared the original draft of the commentary. All authors provided inputs and comments on successive drafts, including the drafting of specific sections. All authors read and approved the final draft.

Competing interests The authors work with several networks and organisations that are named in this paper, and advocate greater support for networks and organisations of these kinds.

Provenance and peer review Commissioned; externally peer reviewed.

Data sharing statement No additional data are available.
Open Access This is an Open Access article distributed in accordance with the Creative Commons Attribution Non Commercial (CC BY-NC 4.0) license, which permits others to distribute, remix, adapt, build upon this work noncommercially, and license their derivative works on different terms, provided the original work is properly cited and the use is non-commercial. See: http:// creativecommons.org/licenses/by-nc/4.0/

\section{REFERENCES}

1. Kruk ME. Globalisation and global health governance: implications for public health. Glob Public Health 2012;7(Suppl 1): S54-62.

2. Jamison DT, Summers LH, Alleyne G, et al. Global health 2035: a world converging within a generation. Lancet 2013;382: 1898-955.

3. Glassman A. Millions saved: how to make sure global health programs work. http://www.theguardian.com/health-revolution/2016/ mar/22/millions-saved-book-healthcare-global-aid-policy (accessed 25 Mar 2016).

4. Stuckler D, McKee M. Five metaphors about global-health policy. Lancet 2008;372:95-7.

5. Shiffman J. Knowledge, moral claims and the exercise of power in global health. Int J Health Policy Manag 2014;3:297-9.

6. Braveman P, Egerter S, Williams DR. The social determinants of health: coming of age. Annu Rev Public Health 2011;32: 381-98.

7. Brown B, Crawford P, Darongkamas J. Blurred roles and permeable boundaries: the experience of multidisciplinary working in community mental health. Health Soc Care Community 2000;8:425-35.

8. Sen K, Bonita R. Global health status: two steps forward, one step back. Lancet 2000;356:577-82.

9. Lavis JN, Robertson D, Woodside JM, et al. How can research organizations more effectively transfer research knowledge to decision makers? Milbank Q 2003;81:221-48, 171-2.

10. Balabanova $D$, McKee $M$, Mills $A$, et al. What can global health institutions do to help strengthen health systems in low income countries? Health Res Policy Syst 2010;8:22.

11. World Health Organization. WHO Commission on Social Determinants of Health—final report. http://www.who.int/social_ determinants/thecommission/finalreport/en/ (accessed 25 Mar 2016).

12. Williams P. The competent boundary spanner. Public Adm 2002;80:103-24.

13. OECD. Paris Declaration on Aid Effectiveness: Ownership, Harmonisation, Alignment, Results and Mutual Accountability. OECD High Level Forum, 28 February-2 March. http://www. oecd.org/dac/effectiveness/34428351.pdf (accessed 25 Mar 2016).

14. Gilson L. Health Policy and Systems Research. 2012 (cited 25 March 2016). http://www.who.int/entity/alliance-hpsr/resources/ alliancehpsr_abridgedversionreaderonline.pdf?ua $=1$

15. Greenhalgh T, Wieringa S. Is it time to drop the "knowledge translation" metaphor? A critical literature review. J $R$ Soc Med 2011;104:501-9.

16. WHO Strategy on Health Policy and Systems Research. WHO. 2012. http://www.who.int/alliance-hpsr/resources/publications/ 9789241504409/en/

17. Loewenson R, Laurell AC, Hogstedt C, et al. Participatory action research in health systems: a methods reader, TARSC, AHPSR, WHO, IDRC Canada, EQUINET, Harare, 2014. http://www. equinetafrica.org/sites/default/files/uploads/documents/PAR\% 20Methods\%20Reader2014\%20for\%20web.pdf (accessed 24 May 2016).

18. Lehmann U, Gilson L. Action learning for health system governance: the reward and challenge of co-production. Health Policy Plan 2015;30:957-63.

19. Nambiar D, Sheikh K. How a technical agency helped scale up a community health worker program: an exploratory study in Chhattisgarh State, India. Health Syst Reform. Published Online First: 10 February 2016.

20. Fischer F. Reframing public policy: discursive politics and deliberative practices. USA: Oxford University Press, 2003:35. 